\title{
CMEARTICLE
}

\section{Clinics in diagnostic imaging (191)}

Mark Christopher Pearce ${ }^{1}$, MD, Garry Choy $^{2}$, MD, Robert Chun Chen ${ }^{3}$, MD
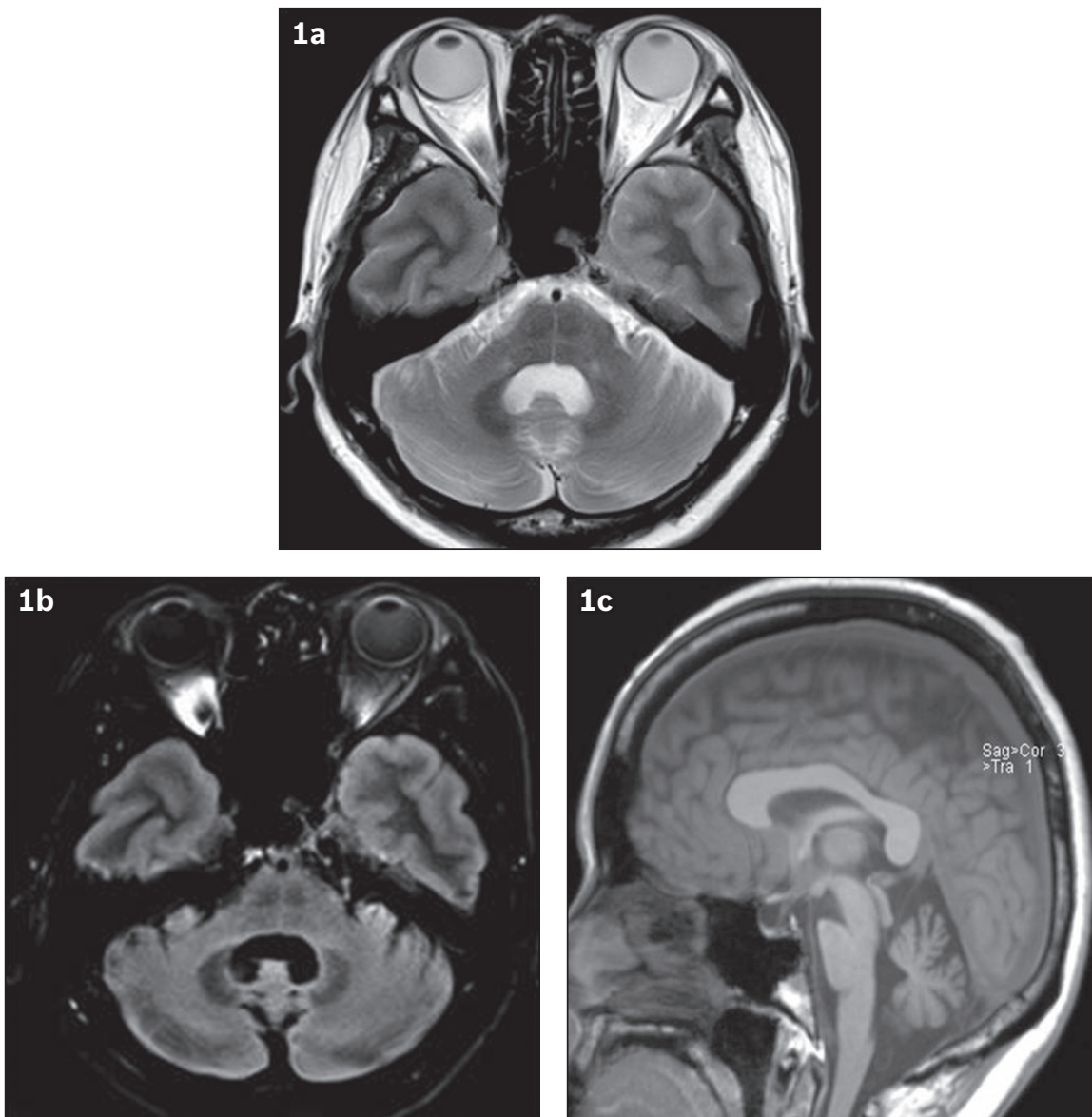

Fig. 1 (a) Axial T2-W; (b) axial T2-W fluid-attenuated inversion recovery; and (c) sagittal T1-W multi-sequence, multi-planar MR images.

\section{CASE PRESENTATION}

A 49-year-old Chinese man with no significant past medical history was evaluated for a two-year history of progressive uncoordinated movements, dysphagia and urinary symptoms. According to his wife, he had given up badminton over a year ago and was increasingly unsteady on his feet. Faced with an extended leave of absence from work, he sought the attention of a neurologist. Clinical examination confirmed marked gait and limb ataxia as well as significant orthostatic hypotension and slightly garbled speech. What do the magnetic resonance (MR) images (Fig. 1) show?

${ }^{1}$ Department of Medical Imaging, Saskatoon Health Region, Saskatoon, Saskatchewan, Canada, ${ }^{2}$ Department of Radiology, Massachusetts General Hospital, Boston, Massachusetts, USA, ${ }^{3}$ Department of Diagnostic Radiology, Singapore General Hospital, Singapore

Correspondence: Dr Robert Chen, Consultant Radiologist, Department of Diagnostic Radiology, Singapore General Hospital, Outram Road, Singapore 169608. robert.chen@sgh.com.sg 


\section{IMAGE INTERPRETATION}

Axial T2-weighted (Fig. 1a) and T2-weighted fluid-attenuated inversion recovery (Fig. 1b) MR images at the level of the cerebellum demonstrate a cruciform pattern of hyperintensity within the pons, representing a hot cross bun sign. Enlargement of the fourth ventricle, with atrophy of the cerebellum and ventral flattening of the pons, is best demonstrated on the sagittal T1weighted sequence (Fig. 1c).

\section{DIAGNOSIS}

Multiple system atrophy-cerebellar type (MSA-C).

\section{CLINICAL COURSE}

Once diagnosed, the patient was subsequently referred to occupational and physical therapy for outpatient neurorehabilitation. His clinical symptoms of neurogenic bladder, recurrent urinary tract infections and orthostatic hypotension were managed by the neurology department to provide symptomatic relief. The patient continued to deteriorate over the next seven years, eventually becoming bedbound and fully dependent on home care for activities of daily living. He eventually passed away from aspiration pneumonia.

\section{DISCUSSION}

MSA-C, also referred to as sporadic olivopontocerebellar atrophy, is a rare and unfortunately fatal neurodegenerative disease. According to Fanciulli and Wenning, the combined prevalence of both MSA-C and MSA-P (multiple system atrophy with Parkinson's subtype) is only around 4.4 cases in $100,000 .^{(1)}$ The peak incidence typically occurs in the sixth decade of life, with no known gender predilection. There are no proven environmental risk factors for MSA-C, although exposure to pesticides, organic solvents and metal dust are classically thought to be associated with the disease. (1) The accumulation of alpha-synuclein glial cytoplasmic inclusions in the pons, cerebellum and inferior olives is thought to result in dysfunction of neurons and oligodendrocytes, which ultimately leads to cellular death. ${ }^{(2)}$ The precise mechanism behind the increase in alpha-synuclein remains unknown, although mutations in several genetic loci, including the COQ2 and GBA genes, have been investigated. ${ }^{(3)}$

The disease typically manifests with prodromal autonomic symptoms, including urinary incontinence, sexual dysfunction and orthostatic hypotension; cerebellar symptoms typically occur later in the disease course. As the disease progresses, patients typically develop limb and gait ataxia, action tremor and abnormal posturing. Dysarthria, dysphagia and drooling generally characterise more advanced disease. ${ }^{(3)}$ MSA-C may also be associated with sleep breathing disorders and rapid-eye movement sleep behavioural disorder. Ultimately, a definitive diagnosis of MSA requires histopathology and is often only obtained postmortem. The diagnostic criteria for probable and possible MSA-C are shown in Table I. Supporting features may include additional clinical and radiological findings from the second consensus statement on the diagnosis of MSA by Gilman et al. ${ }^{(4)}$ Nevertheless, even with consensus criteria, the clinical presentation of MSA-C
Table I. Diagnostic criteria for probable and possible multiple system atrophy-cerebellar type $(\mathrm{MSA}-\mathrm{C}){ }^{(4)}$

\begin{tabular}{|c|c|}
\hline MSA-C & Diagnostic criteria \\
\hline Probable & $\begin{array}{l}\text { A sporadic, progressive, adult-onset (> } 30 \mathrm{yr} \text { ) disease } \\
\text { characterised by: } \\
\text { - A cerebellar syndrome (gait ataxia with cerebellar } \\
\text { dysarthria, limb ataxia or cerebellar oculomotor } \\
\text { dysfunction); and } \\
\text { - Autonomic failure involving urinary } \\
\text { incontinence (inability to control the release of } \\
\text { urine from the bladder, with erectile dysfunction } \\
\text { in males) or an orthostatic decrease of blood } \\
\text { pressure within } 3 \text { min of standing by } \geq 30 \mathrm{mmHg} \\
\text { systolic or } 15 \mathrm{mmHg} \text { diastolic }\end{array}$ \\
\hline Possible & $\begin{array}{l}\text { A sporadic, progressive, adult-onset (> } 30 \text { yr) disease } \\
\text { characterised by: } \\
\text { - A cerebellar syndrome (gait ataxia with cerebellar } \\
\text { dysarthria, limb ataxia or cerebellar oculomotor } \\
\text { dysfunction); and } \\
\text { • } \geq 1 \text { feature suggesting autonomic } \\
\text { dysfunction (otherwise unexplained urinary } \\
\text { urgency, frequency or incomplete bladder } \\
\text { emptying, erectile dysfunction in males, or } \\
\text { significant orthostatic blood pressure decline } \\
\text { that does not meet the level required in probable } \\
\text { MSA); and } \\
\text { • } \geq 1 \text { additional feature: Babinski sign with } \\
\text { hyper-reflexia, stridor, Parkinsonism, atrophy } \\
\text { on magnetic resonance imaging of the } \\
\text { putamen, middle cerebellar peduncles or pons, } \\
\text { hypometabolism of FDG-PET in the putamen, } \\
\text { presynaptic nigrostriatal dopaminergic } \\
\text { denervation on SPECT/PET }\end{array}$ \\
\hline
\end{tabular}

FDG: fluorodeoxyglucose; PET: positron emission tomography; SPECT: singlephoton emission computed tomography

(i.e. adult-onset ataxia with autonomic symptoms) can remain a diagnostic challenge, requiring consideration of toxic causes, vitamin deficiency, infectious states, immune-mediated pathology and other neurodegenerative disorders. ${ }^{(5)}$ Clinical history to determine the chronicity of symptoms, family history, a full neurologic examination and autonomic function testing, including tilt-table testing, are essential. Laboratory investigations should be guided by history and physical findings, but may include testing for Vitamin B1, E or B12, alcohol levels, complete blood count, renal function, liver function tests, human immunodeficiency virus, venereal disease research laboratory or select autoantibodies depending on the clinical picture.

Magnetic resonance (MR) imaging and, infrequently, positron emission tomography (PET) are the primary neuroimaging modalities when MSA-C is suspected. As expected for a disease affecting gait and limb ataxia, multi-sequence MR imaging typically reveals atrophy of the cerebellum, but may also involve selective atrophy of the ventral pons, putamen, middle cerebellar peduncles (MCPs) and inferior olives. ${ }^{(6)}$ Most characteristic for this entity is a cruciform pattern of $\mathrm{T} 2$ hyperintensity within the pons (hot cross bun sign), which is seen in up to $96 \%$ of probable MSA-C cases (Fig. 2); ${ }^{(7)}$ this radiologic pattern is the 

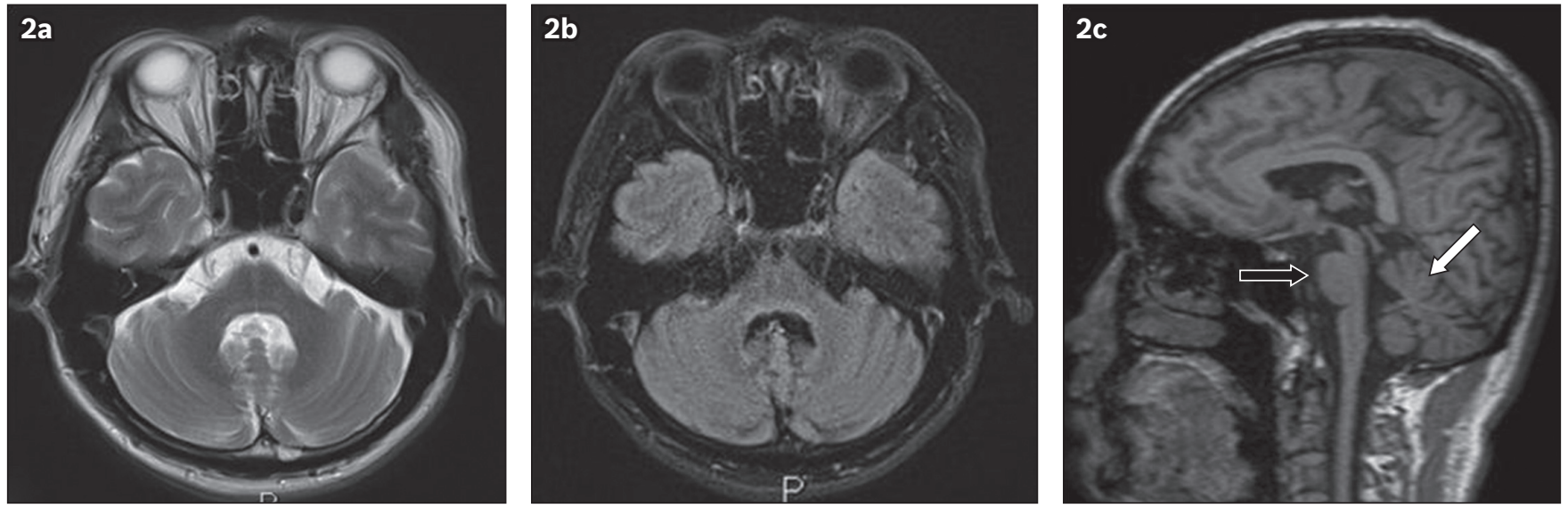

Fig. 2 Multi-sequence multi-planar MR images from a 59-year-old man with chronic alcohol abuse. (a) Axial T2-W; (b) axial T1-W; and (c) sagittal T1-W images show atrophy of the cerebellum (white arrow) with relative sparing of the pons (black arrow). In contrast, the pons in an MSA-C patient is typically flattened. No hot cross bun sign is seen on the axial T2-W images in the pons.
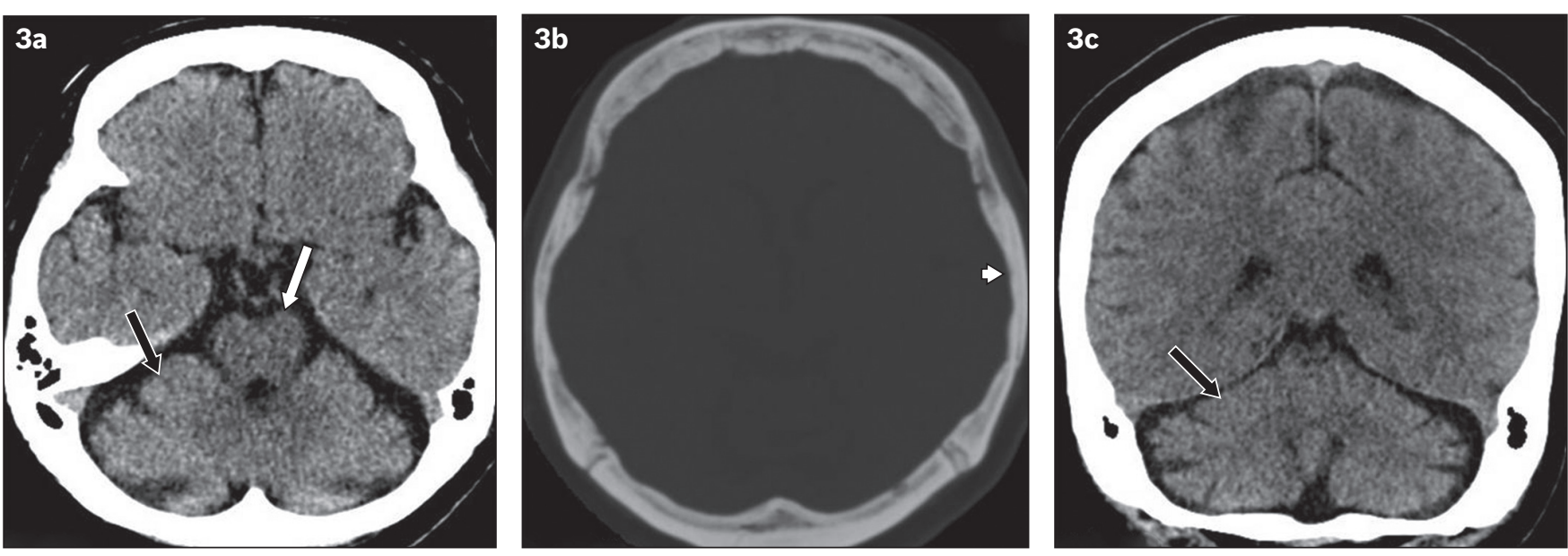

Fig. 3 Multi-planar (a) axial; (b) axial bone window; and (c) coronal CT images in a patient with epilepsy and chronic Dilantin use. There is preferential atrophy of the cerebellum (black arrow in a \& c) with relative sparing of the pons (white arrow) and supratentorial brain. Diffuse bone marrow expansion is also seen (white arrowhead), secondary to chronic Dilantin use.

result of selective degeneration of the myelinated transverse pontocerebellar fibres and pontine neurons, with conservation of the craniocaudally oriented corticospinal tracts. ${ }^{(1,7)}$ Increased signal on the apparent diffusion coefficient map within the MCPs, cerebellum, pons and putamen may also aid in the diagnosis of MSA-C. ${ }^{(8)}$ Furthermore, PET imaging may also reveal fluorodeoxyglucose hypometabolism within the cerebellum and MCPs. ${ }^{(9)}$

The radiologic differential diagnosis of cerebellar atrophy is broad but typically includes more commonly encountered processes such as chronic alcohol ingestion and Dilantin-induced cerebellar atrophy (Fig. 3). These entities will not demonstrate a hot cross bun sign, preferentially result in cerebellar atrophy and typically do not result in pontine flattening. ${ }^{(10)}$ Clinical history is often more helpful in making the diagnosis than imaging. When presented with MR findings suspicious for MSA-C (cruciform T2 hyperintensity of the pons and selective atrophy of the posterior fossa contents), the differential diagnosis is limited to a select few rare entities for which only a handful of cases have been reported in the literature. Spinocerebellar ataxia, in particular Subtypes 2, 3 and 6, can be radiologically indistinguishable from MSA-C. ${ }^{(11)}$ In these instances, genetic testing can help differentiate this inherited neurodegenerative disease from MSA. Additionally, there have been rare case reports of hot cross bun signs occurring in variant Creutzfeldt-Jakob disease (vCJD) and vasculitis, although this is certainly not their typical radiologic presentation. vCJD classically presents with signal abnormality in the posterior thalamus, which is known as the hockey stick sign, ${ }^{(12)}$ while vasculitis may present with supratentorial and infratentorial areas of ischaemia, infarction and vessel wall irregularity. ${ }^{(13)}$ It is important to note that while neuroimaging findings may be highly suggestive of MSA-C, they are ultimately not essential, as the current diagnostic criteria of MSA-C are solely based on clinical findings. As such, neuroimaging may be used in instances of clinical diagnostic uncertainty.

Unfortunately, the prognosis for MSA-C is dismal and includes a slow and progressive period of decline over 5-10 years before death. ${ }^{(14)}$ Interventions are directed at alleviating symptoms and improving quality of life, as there is no effective disease-modifying treatment for its progressive cerebellar ataxia. Medications such as fludrocortisone, oxybutynin and selective serotonin reuptake inhibitors may be used to address commonly encountered symptoms such as orthostatic hypotension, overactive bladder and concomitant depression, respectively. ${ }^{(15)}$ 
ABSTRACT A 49-year-old Chinese man was evaluated for progressive uncoordinated movements, dysphagia and urinary symptoms. Magnetic resonance imaging demonstrated a cruciform pattern of T2-weighted hyperintensity within the pons and selective atrophy of the cerebellar hemispheres and pons. The clinical history and radiological findings were consistent with a diagnosis of multiple system atrophy-cerebellar type. This article discussed the background, proposed mechanisms, diagnosis, radiological characteristics, prognosis and management of multiple system atrophy-cerebellar type.

Keywords: multiple system atrophy cerebellar type, sporadic olivopontocerebellar atrophy, type C

\section{REFERENCES}

1. Fanciulli A, Wenning GK. Multiple-system atrophy. N Engl J Med 2015; 372:1375-6.

2. Ozawa T, Paviour D, Quinn NP, et al. The spectrum of pathological involvement of the striatonigral and olivopontocerebellar systems in multiple system atrophy: clinicopathological correlations. Brain 2004; 127:2657-71.

3. Laurens B, Vergnet S, Lopez MC, et al. Multiple system atrophy: state of the art.
Curr Neurol Neurosci Rep 2017; 17:41

4. Gilman S, Wenning GK, Low PA, et al. Second consensus statement on the diagnosis of multiple system atrophy. Neurology 2008; 71:670-6.

5. Barsottini OG, Albuquerque MV Braga-Neto P, Pedroso JL. Adult onset sporadic ataxias: a diagnostic challenge. Arq Neuropsiquiatr 2014; 72:232-40.

6. Matsusue E, Fujii S, Kanasaki Y, et al. Cerebellar lesions in multiple system atrophy: postmortem MR imaging-pathologic correlations. AJNR Am J Neuroradiol 2009; 30:1725-30.

7. Deguchi K, Ikeda K, Kume K, et al. Significance of the hot-cross bun sign on T2* weighted MRI for the diagnosis of multiple system atrophy. J Neurol 2015; 262:1433-9.

8. Kanazawa M, Shimohata T, Terajima K, et al. Quantitative evaluation of brainstem involvement in multiple system atrophy by diffusion-weighted MR imaging. J Neurol 2004; 251:1121-4.

9. Lee PH, An YS, Yong SW, Yoon SN. Cortical metabolic changes in the cerebellar variant of multiple system atrophy: a voxel-based FDG-PET study in 41 patients. Neuroimage 2008; 40:796-801.

10. Arora R. Imaging spectrum of cerebellar pathologies: a pictorial essay. Pol J Radiol 2015; 80:142-50.

11. Okamoto K, Tokiguchi S, Furusawa T, et al. MR features of diseases involving bilateral middle cerebellar peduncles. AJNR Am J Neuroradiol 2003; 24:1946-54

12. Collie DA, Summers DM, Sellar RJ, et al. Diagnosing variant Creutzfeldt-Jakob disease with the pulvinar sign: MR imaging findings in 86 neuropathologically confirmed cases. AJNR Am J Neuroradiol 2003; 24:1560-9.

13. Abdel Razek AA, Alvarez H, Bagg S, Refaat S, Castillo M. Imaging spectrum of CNS vasculitis. Radiographics 2014; 34:873-94.

14. Low PA, Reich SG, Jankovic J, et al. Natural history of multiple system atrophy in the USA: a prospective cohort study. Lancet Neurol 2015; 14:710-9.

15. Maaß S, Levin J, Höglinger G. Current treatment of multiple system atrophy. Curr Treat Options Neurol 2016; 18:51. 


\section{SINGAPORE MEDICAL COUNCIL CATEGORY 3B CME PROGRAMME} (Code SMJ 201810B)

Question 1. Regarding multiple system atrophy-cerebellar type (MSA-C):

(a) Prodromal autonomic symptoms may include urinary incontinence and sexual dysfunction.

(b) There are no proven environmental risk factors.

(c) MSA-C typically affects males between the ages of 18 and 40 years.

(d) The combined prevalence of MSA-C and MSA with Parkinson's subtype is only 4.4 per 100,000 cases.

Question 2. Regarding patients presenting with cerebellar symptoms in MSA-C:

(a) Clinical differentials should include vitamin deficiency, toxic causes and infectious states.

(b) Dysarthria, dysphagia and drooling generally characterise more advanced disease.

(c) MSA-C may occasionally present with unilateral motor and/or sensory weakness.

(d) Rapid-eye movement sleep behavioural disorders can be seen in MSA-C.

Question 3. With respect to the clinical and radiologic workup of suspected MSA-C patients:

(a) Computed tomography is highly sensitive to the changes of MSA-C.

(b) Magnetic resonance (MR) imaging cannot distinguish between alcoholic cerebellar atrophy and MSA-C.

(c) Laboratory workup may include a complete blood count, Vitamin B1, E or B12, and alcohol levels.

(d) Positron emission tomography may reveal fluorodeoxyglucose hypometabolism in the cerebellum and middle cerebellar peduncles (MCPs).

Question 4. Regarding the evaluation of MSA-C with MR imaging:

(a) Cruciform pattern of T2-weighted hyperintensity within the pons is seen in over $90 \%$ of cases of MSA-C.

(b) Atrophy of the ventral pons, putamen and MCPs may be seen.

(c) Spinocerebellar ataxia, vasculitis and variant Creutzfeldt-Jakob disease may also show a hot cross bun sign.

(d) Characteristic neuroimaging findings are not required to make a diagnosis of MSA-C.

Question 5. Regarding the management and prognosis of MSA-C:

(a) Its natural history is a slow and progressive period of decline over 5-10 years before death.

(b Fludrocortisone and oxybutynin can be used for symptomatic treatment.

(c) Routine follow up MR imaging is recommended for most cases of MSA-C.

(d) Recombinant monoclonal antibodies and prednisone have a proven mortality benefit.

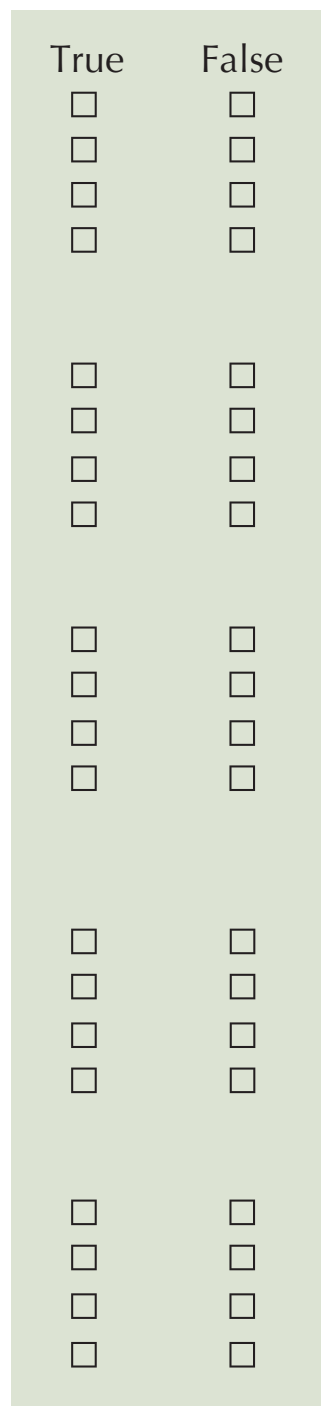

\section{Doctor's particulars:}

Name in full:

MCR no.:

Specialty:

Email:

\footnotetext{
SUBMISSION INSTRUCTIONS:

Visit the SMJ website: http://www.smj.org.sg/current-issue and select the appropriate quiz. You will be redirected to the SMA login page.

For SMA member: (1) Log in with your username and password (if you do not know your password, please click on 'Forgot your password?'). (2) Select your answers for each quiz and click 'Submit'.

For non-SMA member: (1) Create an SMJ CME account, or log in with your SMJ CME username and password (for returning users). (2) Make payment of SGD 21.40 (inclusive of $7 \%$ GST) via PayPal to access this month's quizzes. (3) Select your answers for each quiz and click 'Submit'.

RESULTS:

(1) Answers will be published online in the SMJ December 2018 issue. (2) The MCR numbers of successful candidates will be posted online at the SMJ website by 7 December 2018. (3) Passing mark is $60 \%$. No mark will be deducted for incorrect answers. (4) The SMJ editorial office will submit the list of successful candidates to the Singapore Medical Council. (5) One CME point is awarded for successful candidates. (6) SMC credits CME points according to the month of publication of the CME article (i.e. points awarded for a quiz published in the December 2017 issue will be credited for the month of December 2017, even if the deadline is in January 2018).

Deadline for submission (October 2018 SMJ 3B CME programme): 12 noon, 30 November 2018.
} 